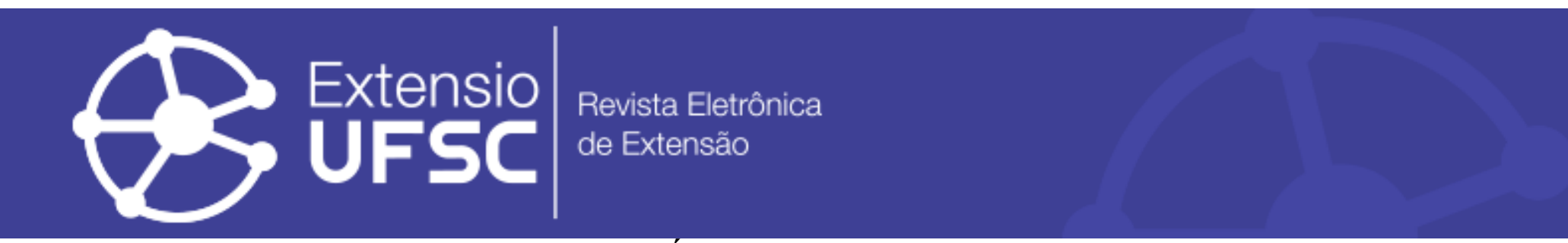

\title{
ESTUDAR ESTRUTURA DA LÍNGUA: A ATIVIDADE EXTENSIONISTA E A EaD COMO ESPAÇOS DE DEMOCRATIZAÇÃO DO CONHECIMENTO
}

\author{
Daniele Bertollo \\ Universidade Estadual do Oeste do Paraná \\ danixbertollo@gmail.com \\ Alcione Tereza Corbari \\ Universidade Estadual do Oeste do Paraná \\ alcione_corbari@hotmail.com
}

Higor Miranda Cavalcante

Universidade Estadual do Oeste do Paraná contato.hmc@live.com

Quézia Cavalheiro Mingorance Ramos
Universidade Estadual do Oeste do Paraná
queziacavalheiro06@hotmail.com

Resumo

Este artigo objetiva apresentar o projeto de extensão Morfologia básica da língua portuguesa: estrutura e formação da palavra, desenvolvido na Universidade Estadual do Oeste do Paraná (campus de Cascavel),bem como refletir sobre a potencialidade da tecnologia na formação inicial e continuada do professor e no movimento de aproximação entre universidade e comunidade. A atividade extensionista teve início em 2018, como projeto piloto, tendo por objetivo central construir e implementar um curso voltado à socialização do conhecimento sobre o nível mórfico da língua portuguesa; em 2019, teve seu status alterado para 'projeto permanente', passando a ser ofertado anualmente. Seu potencial como ferramenta de difusão do conhecimento relativo à estrutura da língua portuguesa levou a alterações metodológicas de maneira a se transformar em uma atividade realizada integralmente a distância. Além de estar contribuindo para a formação inicial e continuada de professores de todo o território nacional, tem desempenhado importante papel na formação dos professores formados e em formação que participam da equipe proponente.

Palavras-chave: Extensão. Formação de Professores. EaD. Estrutura da Língua Portuguesa.

\section{STUDYING LANGUAGE STRUCTURE: EXTENSIONIST ACTIVITY AND E- LEARNING AS LOCUS FOR DEMOCRATIZATION OF KNOWLEDGE}

\begin{abstract}
This article aims to present the university extension project Basic morphology of the Portuguese language: structure and form of the word, developed at Western Paraná State University, as well as to reflect on the potential of technology in the initial and continuing teacher education and in the university-community partnership. The university extension activity began in 2018 as a pilot project, with the main objective of building and implementing a course aimed at the socialization of knowledge about the morphological level of the Portuguese language. In 2019, its status was changed to a 'permanent university extension project', with the proposal to re-offer the course annually. Due to its potential as a tool to diffuse the knowledge of the structure of the Portuguese language, the activity has gone through methodological changes in order to become an activity performed entirely online. In addition to contributing to the initial and continuing teacher education from all over the country, it has played an important role in the training of teachers participating in the proposing team.
\end{abstract}

Keywords: Extension. Teacher Training. E-learning. Structure of the Portuguese Language.

\section{ESTUDIAR LA ESTRUCTURA DEL LENGUAJE: ACTIVIDAD EXTENSIONISTA Y EaD COMO ESPACIOS DE DEMOCRATIZACIÓN DEL CONOCIMIENTO}

Resumen

Este artículo tiene como objetivo presentar el proyecto de extensión Morfología básica de la lengua portuguesa: estructura y formación de lapalabra, desarrollado em Universidad Estatal del Oeste del Paraná, así como reflexionar sobre el potencial de La tecnologia em la formación inicial y continua del profesorado y en el movimiento de aproximación entre universidad y comunidad. La actividad de extensións urgió en 2018 como um proyecto piloto, com el objetivo principal de construir e implementar un curso dirigido a la socialización del conocimiento sobre El nivel mórfico de la lengua portuguesa. En 2019, su estado fue cambiado a 'proyecto permanente', ofreciéndose anualmente. Su potencial como herramienta para la difusión del conocimiento sobre la estructura de la lengua portuguesa ha llevado a cambios metodológicos para convertirse en una actividad realizada a distancia. Además de contribuir a la educación inicial y continua de docentes de todo el territorio nacional, ha desempeñado un papel importante en la capacitación de los participan en el equipo proponente.

Palabras clave: Extensión. Formación del Profesorado. EaD. Estructura de La Lengua Portuguesa. 
Estudar estrutura da língua: a atividade extensionista e a EaD como espaços de democratização do conhecimento

\section{INTRODUÇÃO}

As reflexões presentes neste artigo dão-se em torno do projeto de extensão Morfologia básica da língua portuguesa: estrutura e formaşão da palavra, oferecido pela Universidade Estadual do Oeste do Paraná - Unioeste (campus de Cascavel). A atividade, que teve início em 2018 e tem hoje caráter permanente, é coordenada pela professora doutora Alcione Tereza Corbari, do Centro de Educação Comunicação e Artes, e conta com uma equipe composta por egressos e alunos de doutorado, mestrado e graduação em Letras.

O projeto guia-se pelo objetivo geral de construir e implementar curso em EaD voltado à socialização do conhecimento sobre o nível mórfico da língua portuguesa. Como objetivos específicos, temos:

a) socializar o conhecimento historicamente construído no que tange à morfologia da língua portuguesa, a partir de canais de interação que permitam ultrapassar os limites da academia;

b) motivar reflexões críticas sobre o nível mórfico da língua portuguesa, embasadas em estudos linguísticos;

c) promover o desenvolvimento de conhecimentos que contribuam para a consolidação da qualidade de ensino de graduação em Letras, colaborando para o processo de formação inicial do professor de Língua Portuguesa, bem como para a formação continuada de alunos egressos;

d) contribuir para que o aluno do curso compreenda a língua como sistema estruturado, sujeito a determinadas regras, percebendo a importância do conhecimento gramatical para a compreensão e o uso dos mecanismos da língua portuguesa;

e) criar condições para o domínio da abordagem normativa de questões da morfologia do português, buscando o conhecimento e a compreensão dos princípios, dos elementos constitutivos e dos procedimentos da descrição morfológica pertinentes ao ensino nos níveis Fundamental e Médio;

f) estimular o desenvolvimento de habilidades ligadas ao ensino de língua portuguesa com base em ferramentas digitais.

O projeto envolve dois grupos: um de professores e alunos de graduação e pósgraduação da Unioeste, que propuseram, construíram e implementaram/implementam o curso; outro formado por inscritos no curso como alunos. O curso, que se constitui, então, como parte do projeto, tem como público-alvo principal alunos e egressos de Letras e áreas 
Estudar estrutura da língua: a atividade extensionista e a EaD como espaços de democratização do conhecimento

afins, focando na formação inicial e continuada do professor, mas amplia-se para a comunidade em geral, já que estabelece como pré-requisito para a inscrição apenas formação no Ensino Médio.

Para além de apresentar o projeto, neste texto, fazemos reflexões sobre a importância da tecnologia na formação do professor e no movimento de aproximação dos saberes que circulam na universidade em direção à comunidade. Assim, na próxima seção, fazemos um relato sobre o projeto. Refletimos, na sequência, sobre as potencialidades da Educação a Distância (EaD) como forma de socialização de conhecimentos. Posteriormente, voltamos o olhar à formação do professor e ao ensino de estrutura da língua, foco de nosso projeto. Em seguida, falamos sobre a contribuição da atividade extensionista para a formação dos professores que participam da equipe proponente. Por fim, expomos algumas dificuldades e desafios enfrentados na execução do projeto.

\section{BREVE HISTÓRICO DE UM PROJETO AINDA EM CONSTRUÇÃO}

A atividade extensionista em tela nasceu de uma demanda histórica dos alunos de Letras da Unioeste, por uma formação mais aprofundada no que tange à estrutura da língua portuguesa, o que justifica o objetivo "c)" acima elencado. Levando em conta a relevância das práticas de reflexão linguística, especialmente na formação de professores de língua portuguesa, e algumas dificuldades que surgem ao longo do processo de graduação, bem como na rotina da sala de aula, fizemos a proposição de um curso inicialmente voltado à comunidade local.

Considerando a dificuldade de reunir os alunos em aulas presenciais e a necessidade de ampliar as formas de socialização do conhecimento, propusemos a criação de um curso em ambiente virtual, baseado em videoaulas e em interações na plataforma Moodle (MoodleLetras-Unioeste ${ }^{1}$ ). Tendo um alcance local, o curso iniciado em maio de 2018 finalizou com a aplicação de uma prova presencial em fevereiro de 2019.

No entanto, o projeto vai ganhando corpo e se projetando para alcançar uma população mais abrangente. Tendo em vista a potencialidade da educação a distância no esforço de ampliar o acesso ao conhecimento historicamente acumulado, propusemos, a

\footnotetext{
${ }^{1}$ Link para acesso: http://projetos.unioeste.br/moodle/letras/login/index.php. O acesso ao curso é liberado mediante senha, enviada ao aluno após confirmação da inscrição.
} 
Estudar estrutura da língua: a atividade extensionista e a EaD como espaços de democratização do conhecimento

partir de 2019, um curso que se dá integralmente na modalidade a distância, o que possibilita que interessados de todo o território nacional o acessem.

No primeiro ano do projeto, em 2018, foram elaboradas, gravadas e editadas mais de 60 videoaulas a respeito do nível morfológico da língua portuguesa. As gravações dos vídeos foram feitas na universidade e na residência da professora coordenadora, com equipamentos de seu uso pessoal ou adquiridos com recursos próprios para viabilizar a realização do projeto. O processo de gravação e edição das aulas, na maior parte dos casos, ficou por conta da professora coordenadora. Os outros membros da equipe desempenharam valiosa contribuição, preparando e ministrando aulas. Colaboraram, também, na produção e revisão de material didático e nas atividades implementadas no Moodle, além de terem contribuído com a interação com os alunos do curso e o levantamento dos dados que serviram para avaliação do desemprenho dos inscritos e para a avaliação geral do curso.

As aulas gravadas abordam desde a noção de palavra/vocábulo mórfico, passando pelo estudo da estrutura e formação da palavra, e finalizando com as classes de palavras e mudança de classe. Embora o curso tenha como objetivo central abordar o estudo morfológico a partir do que nos é dado pela gramática tradicional e pelos estudos do estruturalistas, para que os alunos se apropriem desse conhecimento, também buscamos, na medida do possível, instigar reflexões para além dessa perspectiva, como é o caso, por exemplo, da discussão em torno do 'grau', das dificuldades de classificação dos 'advérbios', da necessidade de revisão da lista de 'pronomes retos' dada pela gramática tradicional, entre outros assuntos. Em geral, nas videoaulas, fizemos uma introdução dessas questões, e as aprofundamos nas atividades disponibilizadas no Moodle.

No segundo ano do projeto, 2019, com as aulas já gravadas e algumas atividades já elaboradas, a equipe teve condições de propor novas atividades. Por exemplo, aperfeiçoamos a proposta de analisar criticamente o conhecimento trazido pela gramática tradicional e pela perspectiva estruturalista com a proposição de exercícios que discutem o nível mórfico com base em estudos linguísticos atuais, aprofundando questões levantadas nas videoaulas. Citamos como exemplo as atividades escritas que instigam reflexão sobre a produtividade do estrangeirismo e as atividades que demandavam pesquisa e reflexão sobre função semântico-discursiva do diminutivo e do artigo.

Diferentemente do que ocorreu em 2018, quando as videoaulas e as atividades eram construídas e publicadas no decorrer do curso, em 2019, disponibilizamos todas as 
Estudar estrutura da língua: a atividade extensionista e a EaD como espaços de democratização do conhecimento

videoaulas e as atividades (fóruns de discussão, tarefas, glossários, questionários etc.) noMoodle Letras - Unioestedesde a abertura do curso. Cada aluno pôde realizar as atividades a seu tempo, entre junho e outubro. Em novembro foi aplicada a prova final, também via plataforma Moodle.

Buscando operacionalizar a inscrição e certificação dos participantes, a partir de 2019, o curso foi incluído no sistema de gerenciamento de eventos da Unioeste. As inscrições ocorreram no mês de maio e foram disponibilizadas 150 vagas. Porém, no momento em que se acessou o sistema para verificar se as vagas haviam sido preenchidas, já se registravam 159 inscrições de alunos advindos de diferentes lugares do Brasil. A partir das categorias disponíveis no sistema no momento da inscrição, podemos traçar um perfil geral dos inscritos: 55 professores, 59 estudantes da graduação, 12 estudantes da pósgraduação e 33 membros da comunidade externa. Vale observar que o aluno, embora precise optar por uma categoria no momento da inscrição, pode participar de mais de uma delas, como é o caso dos pós-graduandos que são também professores, por exemplo.

A respeito dos requisitos de certificação, foram certificados os alunos que alcançaram média mínima de 70 pontos, composta pela prova final e pelas atividades diversas, e que atingirem pelo menos $75 \%$ de frequência, considerada conforme o número atividades obrigatórias realizadas.

Vale observar que, em 2019, a procura dos participantes superou a expectativa inicial. No ano anterior, algumas pessoas interessadas em se inscrever não puderam fazê-lo por conta da impossibilidade de realização da prova presencial. No segundo ano do projeto, inscreveram-se no curso alunos de diversas partes do país, uma vez que a oferta se deu integralmente na modalidade $\mathrm{EaD}$, propiciando o compartilhamento de saberes e o desenvolvimento do aprendizado no espaço virtual.

De forma extensa, este projeto alcança um público ainda mais abrangente, na medida em que as aulas produzidas, publicadas em canal do YouTube Lingua PortuguesaQue lindeza. ${ }^{2}$, podem ser acessadas por qualquer pessoa interessada no assunto. Assim, a universidade amplia ainda mais as possibilidades de socialização de conhecimentos que geralmente ficam circunscritos ao meio acadêmico, movimentando a tríade pesquisaensino-extensão também fora de seus muros.

\footnotetext{
${ }^{22}$ Link de acesso ao canal: http://www.youtube.com/linguaportuguesaquelindeza.
} 
Estudar estrutura da língua: a atividade extensionista e a EaD como espaços de democratização do conhecimento

\section{AS POTENCIALIDADES DA EDUCAÇÃO A DISTÂNCIA COMO FORMA DE SOCIALIZAÇÃO DOS CONHECIMENTOS}

Ao pensar na elaboração desse projeto de extensão, partimos do pressuposto de que o conhecimento historicamente acumulado em relação à estrutura da língua contribui para o desenvolvimento de habilidades linguísticas requeridas em diversos contextos de uso da língua. A possibilidade de difusão de tal conhecimento se amplia com o uso das mídias digitais (ROJO; MOURA, 2019), por meio do ensino híbrido e a distância. A popularização de tais mídias facilitou o acesso da população ao conhecimento, visto que, considerando o último levantamento das agências de mídia social We Are Social e Hootsuite (jul./2019), das mais de 7.713 bilhões de pessoas no mundo, 46\% (3.534 bilhões) mantêm ativa uma mídia social (GLOBAL..., 2019, n.p.). Nesse contexto, é preciso que as instituições de ensino saibam associar o crescente uso das tecnologias ao cotidiano acadêmico e promovam ações que envolvam e proporcionem o acesso ao conhecimento de qualidade, isto é, "os mais diversos contextos escolares precisam discutir e se apropriar dessas tecnologias para que os alunos também incorporem em suas vidas as inúmeras possibilidades oferecidas por equipamentos [...] e aplicativos" (COSCARELLI, 2016, p. 11).

Conforme pontua Prado (2005), a incorporação da tecnologia na escola, na vida e na sociedade colabora para a construção de uma cidadania mais democrática e participativa. Desde que usada de forma consciente, crítica e reflexiva, contribui, ainda, para que a escola esteja próxima à realidade de seus alunos, visto que ignorar o desenvolvimento tecnológico e digital pode significar um distanciamento em relação às novas demandas e aos interesses dos alunos.

Nesse contexto, ganham destaque os multiletramentos (ROJO; MOURA, 2012), processo que põe em evidência a necessidade de a escola incorporar novas práticas pedagógicas. Rojo e Moura (2012) citam características dos multiletramentos e dos novos hiper(textos):

Eles são interativos, mais que isso, colaborativos; (b) eles fraturam e transgridem as relações de poder estabelecidas, em especial as relações de propriedade (das máquinas, das ferramentas, das ideias, dos textos) [...]; (c) eles são híbridos, fronteiriços, mestiços (de linguagens, modos, mídias e culturas) (ROJO; MOURA, 2012, p. 23). 
Estudar estrutura da língua: a atividade extensionista e a EaD como espaços de democratização do conhecimento

Tais características são relevantes porque, entre outras potencialidades, abrem espaço para a interação em vários níveis do usuário (leitor/produtor) com vários interlocutores (interface, ferramentas, outros usuários, textos/discursos), alçando o usuário da posição de mero consumidor de produtos culturais a produtor colaborativo.

Assim, as Tecnologias de Comunicação Digital (TCD), no cenário da EaD, propõem um caminho do qual emanam muitas possibilidades para realização de uma aprendizagem "na qual o protagonismo do estudante, os aspectos colaborativos e interativos são postos em evidência" (GRANETTO; DAL MOLIN; LUDIVICO, 2015, p. 141).

Entendemos ainda que o ensino a distância, embora distante fisicamente, pode se constituir como uma oportunidade de aproximação do aluno de seu próprio processo de aprendência. A realização das atividades na modalidade a distância possibilita o compartilhamento de conhecimento de uma forma mais interativa, considerando-se os diversos recursos e as diferentes ferramentas digitais disponibilizados, que permitem que o aluno e o professor mobilizem diferentes hipermídias (SANTAELLA, 2007; LEMKE, 2002) ao longo de uma interação. Nesse sentido, a EaD pode ser considerada "uma modalidade democrática e inclusiva, devido ao apoio das tecnologias de comunicação digital (TCD) que superam problemas, tais como distância, tempo e dificuldades de aprendizagem" (GRANETTO; DAL MOLIN; LUDIVICO, 2015, p. 141).

Os ambientes virtuais de ensino e aprendizagem propõem um fazer pedagógico de modo fluido, no qual os processos de ensinar e aprender se deem de forma articulada, sendo a interação a chave e a meta de todo o processo. A plataforma Moodle constitui, neste projeto, o cenário para a atuação e o encontro de alunos e equipe responsável. Nessa peça, todos os atores têm importância no processo de aprendência, dado que a construção do saber é resultado de um processo de cooperação, de desafios e constante interação entre professores, tutores, alunos e objetos técnicos (LUDOVICO; DAL MOLIN, 2014).

Essa forma de construção e compartilhamento de conhecimento abre espaço para novos pontos de partida, novas descobertas, resultando numa teia interativa entre pessoas e aparatos tecnológicos. Muitas das atividades propostas na plataforma sugerem, por meio de reflexões teóricas-práticas, que o aluno empreenda suas investigações sobre os temas estudados, fomentando o aprendizado pautado nos princípios de cooperação e autonomia. 
Estudar estrutura da língua: a atividade extensionista e a EaD como espaços de democratização do conhecimento

A partir das contribuições de Lévy (2010), podemos considerar que, no contexto atual, a $\mathrm{EaD}$, com suas especificidades e potencialidades, contribui para a transformação da prática pedagógica e para a democratização do acesso ao saber, uma vez que o ensino pode transpor barreiras geográficas, chegando a lugares isolados e alcançando pessoas que, talvez, jamais teriam a oportunidade de ter contato com atividades de extensão ofertadas por Instituições de Ensino Superior (IES) públicas ou que teriam dificuldade de adaptar suas rotinas para frequentar um curso presencial.

Entendemos, assim, que o curso oferecidos e inclui na dinâmica de novos processos de aprendência e de letramentos, contribuindo para confirmar aquilo que observa Aquino (2007): a educação a distância se revela, cada vez mais, como uma alternativa de ensino-aprendizagem.

\section{APRENDER E ENSINAR A ESTRUTURA DA LÍNGUA POR MEIO DA EaD: EM FOCO, A FORMAÇÃO DO PROFESSOR DE PORTUGUÊS}

Quando se reflete sobre a formação de professores de língua portuguesa, muito mais do que aprender conteúdos gramaticais, busca-se um caminho para ensinar o idioma. Trata-se de uma questão que vai além da teoria, pois transpassa campos de ordem didáticopedagógica e compõe a vida dos professores na inerência de sua atividade: alavancar, incentivar, estimular, desenvolver a competência linguística em seus educandos.

Há muitas reflexões sobre ensinar ou não estrutura da língua na escola, questões que discutem, de modo preponderante, a pertinência do estudo metalinguístico, pois suscita recorrentemente a dúvida do que seria adequado no ensino de língua portuguesa: ensinar a língua ou sobre a língua? Há, atualmente, uma posição ponderada acerca da temática que almeja atrelar o ensino de gramática a uma nova perspectiva que busca fazer o aluno refletir sobre seu uso efetivo, considerando o convívio com as variantes linguísticas, inclusive a padrão.

Dessa discussão emergem diferentes posições sobre o ensino da gramática: Perini (2010), por exemplo, defende que o objetivo do ensino de gramática é o exercício do pensamento científico; Travaglia (2011) elenca outros objetivos, como o acesso à informação cultural e a instrumentalização dos alunos com recursos para aplicações práticas; Bechara (2006) diz que o objetivo do ensino de gramática é possibilitar ao aluno 
Estudar estrutura da língua: a atividade extensionista e a EaD como espaços de democratização do conhecimento

escolher que língua usar em cada situação comunicativa; Antunes (2003) defende que a escola precisa deixar de recorrer a uma gramática totalmente descontextualizada em relação aos usos que fazemos da língua, em prol de um ensino que possa contribuir de fato com a ampliação das habilidades sociolinguísticas dos alunos.

Os Parâmetros Curriculares Nacionais (PCNs), por sua vez, citam que o objetivo do ensino desse conteúdo é possibilitar ao aluno dominar a língua nas mais diversas situações de uso (BRASIL, 1998) e, nesse caso, o ensino de gramática permitiria ao aluno constituir "um conjunto de conhecimentos sobre o funcionamento da linguagem e sobre o sistema linguístico relevantes para as práticas de escuta, leitura e produção de textos" (BRASIL, 1998, p.52).

Já para Neves (2008, p. 52), ensinar eficientemente a língua é “propiciar e conduzir a reflexão sobre o funcionamento da linguagem [...] indo pelo uso linguístico, para chegar aos resultados de sentido". Portanto, estudar o funcionamento da língua e seu uso no exercício do trabalho com a gramática não pode ser tomado como uma atividade infrutífera, estéril, mas sim como um meio de se desenvolverem competências comunicativas.

Por esse viés, a autora salienta que devem ser contemplados os registros da fala "culta" e "distensa", pois só haverá sentido e exercício pleno da linguagem se "as escolhas e arranjos estiverem adaptados às condições de produção, aí incluídos os participantes do ato linguístico" (NEVES, 2008, p. 53). Ou seja, essa perspectiva de ensino embasa-se na perspectiva de que o falante, diante das várias opções de que dispõe, escolhe uma dessas opções para construir seu enunciado. Assim, seria atribuição do professor interagir com o aluno no processo de conhecimento dessas opções e na explicação do(s)porquê(s) das escolhas.

É importante lembrar que os colégios estaduais e as escolas municipais de todo o Brasil estão se adequando a um novo documento que tem a incumbência de nortear seus currículos, a Base Nacional Comum Curricular (BNCC). Trata-se de um documento que possui caráter normativo e definidor das aprendizagens essenciais que os alunos devem desenvolver em todas as etapas de aprendizagem. No que se refere à disciplina de língua portuguesa, a BNCC acaba dialogando com os documentos oficiais anteriores, enfocando o trabalho com o texto, visando ao desenvolvimento da habilidade de ler e escrever em atividades sociais diversas. Nesse caso, a BNCC apenas incorpora uma visão mais 
Estudar estrutura da língua: a atividade extensionista e a EaD como espaços de democratização do conhecimento

atualizada e reafirma sua perspectiva enunciativo-discursiva da linguagem. A proposta do documento centra-se em assumir o texto:

[...] como unidade de trabalho e as perspectivas enunciativo-discursivas na abordagem, de forma a sempre relacionar os textos a seus contextos de produção e o desenvolvimento de habilidades ao uso significativo da linguagem em atividades de leitura, escuta e produção de textos em várias mídias e semioses (BRASIL, 2018, p. 67).

Ao se considerar a tradição dos estudos gramaticais no ensino básico e as atuais propostas de transposição didática desse saber historicamente acumulado, entende-se que o conhecimento da perspectiva apresentada nos compêndios gramaticais constitui um dos requisitos para que o professor consiga propor um trabalho em conformidade com as orientações teóricas mais atuais, inclusive com aquelas apresentadas nos PCNs (BRASIL, 1998) e na BNCC (BRASIL, 2018). Considera-se que esse conhecimento é fundamental para que o professor possa superar a perspectiva tradicional em direção à observação da língua em uso, ampliando as condições de reflexão sobre o trabalho com a descrição e análise de estruturas da língua.

O projeto apresenta-se, assim, como possibilidade de revisão de conteúdos e aprofundamento de conhecimentos relativos à estrutura e formação da palavra, focalizando o conhecimento e a reflexão sobre os conceitos de morfologia presentes na gramática tradicional. Porém, não se limita a isso, uma vez que também promove reflexões e atividades com base em estudos linguísticos que questionam o estudo da palavra, herança dos estudos gregos, e mesmo algumas interpretações promovidas pelo Estruturalismo no que tange ao estudo do nível morfológico, conforme já explicitado anteriormente.

Nesse exercício de crítica e reflexão, pretendemos contribuir para que o professor, ao estudar gramática, reflita sobre o uso linguístico, sobre o exercício da linguagem e para que a interação constitua o lugar em que se deve observar o uso da língua, tendo sempre em vista que a gramática rege a produção de sentido (NEVES, 2008), o que surtirá efeitos na forma como lida com a gramática da língua em sala de aula.

Os objetivos do ensino de gramática citados por linguistas e por documentos oficiais, como os PCNs (BRASIL, 1998) e a BNCC (BRASIL, 2018), apontam para a necessidade de uma articulação entre leitura, produção de texto e análise linguística, pois o objetivo do ensino de gramática é ampliar a capacidade de interação do aluno em diferentes contextos sociais. Partindo de tais orientações, entende-se que o acesso ao conhecimento 
Estudar estrutura da língua: a atividade extensionista e a EaD como espaços de democratização do conhecimento

historicamente acumulado em relação à estrutura da língua contribui para o desenvolvimento de habilidades linguísticas requeridas em diversos contextos de uso. A possibilidade de difusão de tal conhecimento se amplia com o uso de recursos tecnológicos, por meio do ensino a distância.

A utilização de ferramentas tecnológicas na promoção do ensino a distância atua no meio educacional não só como instrumento de ensino, mas também como fator importante para a quebra de estereótipos no que tange às metodologias educacionais. Novas linguagens são incorporadas atreladas a novos procedimentos que possibilitam inúmeras formas de interação. Não há nada mais coerente do que promover a autonomia em um mundo irreversivelmente globalizado.

No ensino a distância, os espaços não estão mais limitados por tijolos e muros, o tempo flui sem hora tão exata para começar e acabar, os alunos conversam, intercambiam ideias e materiais de modo virtual, propondo que professores e alunos sejam curiosos e construtores do conhecimento. Os diálogos já não se limitam somente ao professor e a um pequeno grupo de alunos, são criadas redes de interconexão, possibilitando o compartilhando de informações, conteúdos e experiências com diferentes pessoas (SOUZA; SARTORI; ROESLER, 2008).

Essa evolução paradigmática na formação docente prevê o uso tecnológico ético, crítico, consciente e competente. Não há mais possibilidade de não se refletir a formação tecnológica na formação de professores, seja na modalidade presencial, seja no ensino a distância. De acordo com Alvareli (2012),

Formação tecnológica envolve aprender a trabalhar com os recursos e ferramentas tecnológicas (Internet, computador, ambientes virtuais ou digitais de aprendizagem, fóruns, chat, e-mail, etc.), sabendo destiná-los adequadamente para serem utilizados em momentos específicos da prática docente. Não é só saber usar, é saber como, para que finalidade, por qual razão ou necessidade a tecnologia pode ou deve ser utilizada (ALVARELI, 2012, p.50).

Rojo e Moura (2012) chamam a atenção para a necessidade de as escolas, antes de pensar em disciplinar o uso das TIC, precisa pensar em como tais usos, já bastante frequentes pelos alunos, podem se relacionar às práticas institucionais de ensino/aprendizagem. Para os autores, os alfabetismos requeridos pelas práticas de multiletramentos precisam se direcionar "para as possibilidades práticas de que os alunos se transformem em criadores de sentidos" (ROJO; MOURA, 2012, p. 29). 
Estudar estrutura da língua: a atividade extensionista e a EaD como espaços de democratização do conhecimento

Vale observar também que ainda é um desafio a formação tecnológica dos professores, mesmo com a inserção cada vez mais enfática de novos meios de comunicação em sua vida cotidiana. No entanto, esse deve ser um esforço coletivo das universidades, dos governos e dos professores, uma vez que dominar ferramentas tecnológicas e digitais pode auxiliar não só nas práticas docentes, mas também na formação e atualização do próprio professor, tornando-o cada vez mais capaz de responder aos questionamentos e às demandas de um mundo em constante movimento.

A habilidade de conduzir o próprio processo de desenvolvimento formativo deve ser motivada permanentemente e, ao encontro disso, os ambientes virtuais surgem como amplas possibilidades na formação inicial e continuada. Entende-se que o ensino a distância, na modalidade virtual,ainda é uma realidade em construção, por isso acaba gerando constantes inovações a serem aprendidas e otimizadas na formação e prática docente. Acredita-se, portanto, que o projeto contribui para uma formação pautada nas tendências atuais de ensino, valorizando o conhecimento e priorizando a autonomia do aluno participante.

Destacamos que a forma como o projeto vem se construindo contribui para a transformação de nossa própria prática pedagógica, porque nos movimenta para o uso de recursos e práticas pedagógicas que antes não utilizávamos nas aulas presenciais, e para a democratização do acesso ao saber, em especial por viabilizar a participação de alunos de todo o território nacional. A essa discussão soma-se também o fato de a educação a distância se revelar, cada vez mais, como uma alternativa de ensino-aprendizagem, "uma opção moderna, viável e que facilita a re(aproximação) das pessoas com o ensino" (AQUINO, 2007, p. 07), o que é um dos objetivos das atividades extensionistas propostas pela universidade.

\section{ENSINANDO TAMBÉM SE APRENDE: CONTRIBUIÇÕES DO PROJETO NA FORMAÇÃO DOS PROFESSORES DA EQUIPE PROPONENTE}

Conforme explicitado, o curso oferecido como parte do projeto apresenta-se como possibilidade de revisão e aprofundamento de conhecimentos relativos à estrutura e formação da palavra, focalizando o conhecimento e a reflexão sobre os conceitos de 
Estudar estrutura da língua: a atividade extensionista e a EaD como espaços de democratização do conhecimento

morfologia presentes na gramática tradicional e considerando também estudos linguísticos pautados nesse nível de análise.

Nesta seção, chamamos a atenção para o fato de que, na dinâmica de fazer movimentar o curso, os professores que participam da equipe proponente também vão enriquecendo seu repertório de conteúdos, pois, para ensinar, precisam aprofundar seus conhecimentos. Assim, o projeto contribui também para a formação inicial e continuada desses professores, de graduandos a doutores, porque instiga a investigação do nível mórfico da língua a partir de pesquisas linguísticas, o que nem sempre se consegue fazer dentro do currículo dos cursos de graduação e pós-graduação.

Durante o curso de graduação, visto a gama de conteúdos a ser explorada, o tempo pode ser insuficiente para pensar nas inúmeras implicações da estrutura da língua em seus contextos de uso. Assim, o projeto propõe tempo e espaço para essas reflexões envolvendo o nível mórfico da língua.

Aaprendência não se restringe, porém, aos conhecimentos linguísticos. As atividades têm permitido ampliar as formas de ensiná-los, já que, para a maioria dos envolvidos, o ensino a distância ainda se constituía como uma prática nova no papel de professor. Conforme o projeto se transcorre, mais habilidades vão sendo desenvolvidas, quer em relação à forma de organizar e trabalhar o conteúdo, quer no que tange às técnicas de gravação e edição de videoaulas ou às interações com os alunos do curso.

Nesse sentido, o projeto contribui para a consolidação da qualidade de ensino de graduação em Letras de nossa universidade não só por oferecer aos acadêmicos a oportunidade de fazer, no papel de aluno, um curso de extensão sobre estrutura da língua, mas também por oportunizar a acadêmicos, mestrandos, doutorandos e egressos, bem como à professora coordenadora do projeto, o desenvolvimento de habilidades ligadas ao ensino de língua portuguesa com base em ferramentas digitais.

\section{CONSIDERAÇÕES FINAIS: DIFICULDADES E DESAFIOS ENCONTRADOS}

Levar a cabo a proposta do projeto aqui descrito não é tarefa fácil. Demanda, de toda a equipe envolvida, não só o estudo aprofundando do nível mórfico da língua portuguesa, considerando as perspectivas da gramática tradicional e da Linguística, mas também o desenvolvimento de conhecimentos e habilidades relacionados às ferramentas tecnológicas e aos ambientes virtuais de aprendizagem. O próprio exercício de dar aula 
Estudar estrutura da língua: a atividade extensionista e a EaD como espaços de democratização do conhecimento

perante a câmera constitui um desafio bastante significativo no processo, mesmo para aqueles que já atuam como professores, haja vista se tratar de uma forma de interação significativamente diferente daquela promovida na modalidade presencial.

No atual movimento de desvalorização do conhecimento, do professor e do papel social da universidade, fazemos questão de pontuar também as dificuldades envolvidas no que tange ao empenho de tempo e de recursos financeiros ao projeto. Durante o ano de 2018, para que os objetivos fossem atingidos, a coordenadora dedicou ao projeto muitas horas semanais para além da carga-horária inicialmente prevista e muito além da carga-horária que é considerada em seu regime de trabalho. A execução do projeto demandou, inclusive, e de forma recorrente, trabalho durante as madrugadas e nos finais de semana.

Para além disso, registramos que todo o investimento financeiro para compra de programas de computador e de equipamentos para a filmagem e edição dos vídeos teve como fonte os recursos próprios da coordenadora do projeto.

Embora estas tenham sido condições já consideradas na proposição da atividade extensionista, não podemos deixar de registrar que o projeto só se materializou perante tal esforço pessoal, no sentido de energia, tempo e recurso financeiro investidos. Da mesma forma, os demais integrantes da equipe proponente não mediram esforço para que a projeto proposto não só se realizasse como também superasse as expectativas iniciais.

Em outros tempos, poderíamos concluir esse texto sem ter de ficar explicitando questões que são tão comuns e evidentes para quem está inserido na universidade. Mas os tempos são outros, infelizmente! Estamos em tempos em que é preciso desconstruir discursos que visam a desmoralizar a universidade pública.

Observamos, porém, que tais dificuldades aqui relatadas, no entanto, não impedem que continuemos a contribuir para a socialização do conhecimento. A partir deste ano, estamos propondo, como forma de continuidade do curso de Morfologia, um projeto voltado ao nível sintático da língua portuguesa, com o desenvolvimento de novos cursos. Esse esforço, feito por toda a equipe envolvida, volta-se para o objetivo de contribuir para consolidar a função social por excelência da universidade pública e para inseri-la em novos contextos educacionais, mais abrangentes e inclusivos. Esta é mais uma das muitas balbúrdias que fazemos, professores e alunos, na universidade pública! 
Estudar estrutura da língua: a atividade extensionista e a EaD como espaços de democratização do conhecimento

\section{AGRADECIMENTOS}

Agradecemos ao Centro de Educação, Comunicação e Artes e à Unioestepela possibilidade de propormos este projeto. E fazemos aqui um agradecimento especial a todos os colaboradores do projeto, alunos de graduação, mestrado, doutorado e egressos, que não figuram como autores deste artigo. Todos foram essenciais para que o projeto fosse criado e o são para que continue a ser implementado em todo o território nacional.

\section{REFERÊNCIAS}

ANTUNES, Irandé. Aula de português: encontro e interação. São Paulo: Parábola Editorial, 2003.

AQUINO, R. Educação a distância: facilitadora do acesso à formação profissional. Augustus, Rio de Janeiro, p. 01-08, 2007.Disponível em: http://apl.unisuam.edu.br/augustus/index.php?option $=$ com content\&view $=$ article\&id $=1$ 24:educacao-a-distancia-facilitadora-do-acesso-a-formacao-educacional\&catid=44:edicao24-artigos\&Itemid=74. Acesso em: 07 abr. 2018.

ALVARELI, L. V. G. Auto-heteroecoformação tecnológica experienciada por um professor atuante na plataforma Moodle sob a perspectiva da Complexidade. 2012. Tese (Doutorado em Linguística Aplicada e Estudos da Linguagem) - Programa de Estudos Pós-Graduados em Linguística Aplicada e Estudos da Linguagem, Pontifícia Universidade Católica de São Paulo, São Paulo, 2012.

BECHARA, E. Gramática escolar da língua portuguesa. Rio de Janeiro: Lucerna, 2006.

BRASIL. Base Nacional Comum Curricular. Brasília: MEC, 2018.

BRASIL. Parâmetros curriculares nacionais: língua portuguesa: ensino fundamental. Brasília: MEC, 1998.

COSCARELLI, C. V. Tecnologias para aprender. São Paulo: Parábola Editorial, 2016.

DUART, J. M.; SANGRA, A. Aprender en la virtualidad. Barcelona: Gedisa, 2000.

GLOBAL Internet use accelerates. [S.l.]: We Are Social/Hootsuite, 2019. Disponível em: https://wearesocial.com/blog/2019/01/digital-2019-global-internet-use-accelerates.

Acesso em: 09 set. 2019.

GRANETTO, J. C.; DAL MOLIN, B. H; LUDIVICO, F. M. Educação a Distância como Modalidade Inclusiva: e-Sipris. Revista Científica em Educação a Distância,[S.l.], v. 5, 
Estudar estrutura da língua: a atividade extensionista e a EaD como espaços de democratização do conhecimento

n. 2, jan. 2015. Disponível em:

http://eademfoco.cecierj.edu.br/index.php/Revista/article/view/220/140. Acesso em: 31 maio 2019.

LEMKE, J. L. Travels in Hipermodality. Visual Communication, [S.l.], v. 1, n. 3, p. 299325, out. 2002. Disponível em:

https://doi.org/10.1177/147035720200100303https://journals.sagepub.com/doi/10.1177 /147035720200100303. Acesso em: 11 set. 2019.

LÉVY, P. Cibercultura. Trad. Carlos Irineu da Costa. 3. ed. São Paulo: Editora 34, 2010.

LUDOVICO, F. M.; DAL MOLIN, B. H. Educação a distância: um script para muitos atores.In:ENCONTRO INTERMEDIÁRIO DO GRUPO DE PESQUISA CONFLUÊNCIAS DA FICÇÃO, HISTÓRIA E MEMÓRIA NA LITERATURA E NAS DIVERSAS LINGUAGENS, 3., 2014, Cascavel, Anais... Cascavel: Edunioeste, 2014. p. 34-46. Disponível em: http://www.seminariolhm.com.br/home/wpcontent/uploads/2014/07/ANAIS-DO-III-ENCONTRO-INTERMEDIARIO-GRUPODE-PESQUISA-CONFLUENCIAS-DA-FICCAO.pdf. Acesso em: 15 abr. 2019.

NEVES, M. H. M. A gramática: conhecimento e ensino. In: AZEREDO, J. C. (org.). Línguaportuguesa em debate: conhecimento e ensino. 5 ed. Petrópolis: Vozes, 2008. p.52-73.

PARANÁ. Diretrizes curriculares da educação básica: língua portuguesa. Curitiba: SEED, 2008.

PERINI, M. Gramática do português brasileiro. São Paulo: Parábola, 2010.

PRADO, M. E. B. B. Articulações entre áreas de conhecimento e tecnologia. Articulando saberes e transformando a prática. In: ALMEIDA, M. E. B.; MORAN, J. M. (org.). Integração das tecnologias na educação. Brasília: Ministério da Educação; SEED, 2005. p. 54-58.

ROJO; R. H. R.; MOURA, E. Letramentos, mídias, linguagens. São Paulo: Parábola Editorial, 2019.

ROJO, R. H. R.; MOURA, E. Multileramentos na escola. São Paulo: Parábola Editorial, 2012.

SANTAELLA, L. Linguagens líquidas na era da mobilidade. São Paulo: Paulus, 2007.

SOUZA, A. R. B.; SARTORI, A. S.; ROESLER, J. Mediação pedagógica na Educação a Distância: entre enunciados teóricos e práticas construídas. Revista Diálogo Educacional, Curitiba, v.8, n.24, p.327-339, maio/ago. 2008.

TRAVAGLIA, L. C. Gramática: ensino plural. 5. ed. São Paulo: Cortez, 2011.

Recebido em: 18/10/2019

Aceito em: 16/03/2020 